\title{
Breeding structure of a colonising species: Aedes albopictus (Skuse) in the United States
}

\author{
William C. Black IV*, \\ James A. Ferrari*, \\ Karamjit S. Rai* and \\ Dan Sprenger $\dagger$
}

\author{
* Department of Biological Sciences, \\ University of Notre Dame, Notre Dame, IN 46556, \\ U.S.A. \\ † Harris County Mosquito Control District, Houston, \\ TX 77054, U.S.A.
}

\begin{abstract}
Allelic and genotypic frequencies were monitored at seven enzymatic loci in newly established Aedes albopictus (Skuse) populations in the United States. Populations were sampled within the cities of New Orleans, Louisiana, Houston, Texas, three counties surrounding Houston, Memphis, Tennessee, Jacksonville, Florida, and Evansville and Indianapolis, Indiana. Unique alleles and relatively high levels of heterozygosity were detected in New Orleans, Houston, surrounding counties and Indianapolis suggesting relatively large and independent introductions in these cities. No unique alleles and low heterozygosities were detected in Memphis, Evansville and Jacksonville suggesting that a population bottleneck may have accompanied the founding of these populations. The bottleneck may have resulted from a small number of founding individuals or may have been generated through repeated control efforts. Genetic distance estimates indicated that Houston, New Orleans and Indianapolis were genetically similar. Evansville and Memphis were also found to be similar. Significant differentiation of allele frequencies existed among and within cities. Variance in allele frequencies among all samples was partitioned into the variance among cities and among locations within cities. Most of the variance was attributable to local differentiation. The most parsimonious explanation of this result is that much genetic drift aceompanied the establishment of local populations in cities and that there has been little subsequent gene flow. Analysis of genotypic frequencies detected a slight but consistent excess of homozygotes suggesting inbreeding.
\end{abstract}

\section{INTRODUCTION}

A colonising species is defined as one which has historically demonstrated the capacity to extend its range into new types of habitats or previously unoccupied territory (Baker and Stebbins, 1965; Parsons, 1983). Colonisation of new habitats is considered fundamental in many models of speciation (Dobzhansky, 1970; Lewontin, 1974; Mayr, 1963; Wright, 1978) and as such the genetics and ecology of colonising species have been studied extensively (Baker and Stebbins, 1965; Parsons, 1983 for review). Several studies have been made on the population biology and genetics of recently colonised species. However because colonisations usually involve few individuals, the event may go undetected for many years with the result that formal studies are usually conducted long after colonisation (e.g. Anolis grahami in Bermuda in 1909 (Taylor and Gorman, 1975), Musca autumnalis in Nova Scotia in 1952 (Bryant et al., 1981), Oryctolagus cuniculus in Australia in 1788 (Fenner, 1965)). There are few if any studies of the popula- tion biology of a species in the process of colonisation.

The recent introduction of the medically significant mosquito, Aedes albopictus (Skuse), into the United States provides a rare opportunity to study the population genetics of a species in the process of colonising a new continent. Historically, Ae. albopictus has been a remarkably successful colonising species. It is thought to have originated in southeast Asia (Smith, 1956) and spread as far west as Madagascar and east through the Indomalayan and Oriental regions, China and Japan (Ho et al., 1973; Huang, 1972; Knight and Stone, 1977). It became established in Hawaii between 1830 and 1896 (Hardy, 1960; Joyce, 1961) and within the past 20 years has colonised the Solomon and Santa Cruz Islands in the South Pacific (Belkin, 1962; Elliott, 1980; Pashley and Pashley, 1983). An adult female was recovered from a light trap in Memphis, Tennessee in June, 1983 (Reiter and Darsie, 1984). Populations were found throughout Harris County, Texas in August, 1985 (Sprenger and Wuithiranyagool, 1986). 
During the summer of 1986 the species was found to be widely distributed in the United States as far west as San Antonio, Texas, east to Jacksonville, Florida and north throughout the midwest from Kansas City to Indianapolis, Indiana.

Allozyme analysis of populations throughout the world range of Ae. albopictus suggest that U.S. populations originated in northern Japan (Black and Rai, unpublished). Presumably Ae. albopictus was introduced into the United State in commercial shipments (possibly of tyres). Ae. albopictus larvae and pupae were found in tyres shipped to Los Angeles from Vietnam (Eads, 1972). In the U.S. it has been most commonly found in tyre yards, although we have collected it from a variety of containers (e.g., refrigerators, stoves and cans) discarded along roadways. The species has been collected from tree holes in several locations (M. Sinsko, personal communication). Mosquitoes collected throughout the U.S. are freeze tolerant and capable of diapause under laboratory conditions suggesting that the mosquito may become permanently established in the United States (Hawley et al., 1987).

To study the population genetics of Ae. albopictus in the initial stages of colonisation, adults and eggs were collected from a number of cities during the summer and fall of 1986 . Numerous collections were made within the cities of Houston and New Orleans to determine the initial degree of genetic isolation among local populations. By analysing the amount of genetic differentiation within and among cities we sought to describe the kinds of changes in breeding structure that accompany colonisation.

\section{METHODS}

Adult mosquitoes were collected at single locations in Memphis and Evansville, four locations in New Orleans, and three counties surrounding Houston (fig. 1). At each location adults were captured with aspirators and transferred to a cage containing cotton soaked with water and honey to minimise mortality. Collections were returned live to the local laboratory facilities and frozen in liquid nitrogen. Upon returning to Notre Dame, mosquitoes were transferred to a $-70^{\circ} \mathrm{C}$ freezer to await electrophoresis. Eggs were shipped to Notre Dame from Houston, Jacksonville and Indianapolis. They were reared to adults in our insectary and frozen for electrophoresis.

Allozymes were resolved at 7 loci using starch and vertical polyacrylamide gel electrophoresis
(Black and Krafsur, 1984). Mosquitoes were ground in $25 \mu \mathrm{l}$ of grinding buffer (Black and Krafsur, 1985a) for acrylamide gels and $15 \mu$ l of grinding buffer for starch gels. PGI (Phosphoglucoisomerase) and ACON (Aconitase) were resolved on polyacrylamide gels using System A of Black and Krafsur (1985a). EST (Esterase) was resolved with System B. PGM (Phosphoglucomutase) was resolved on starch gels using the TEMM system described by Yong et al. (1982). HAD (Hydroxyl Acid Dehydrogenase), $\mathrm{MDH}$ (Malic acid dehydrogenase) and IDH (Isocitrate dehydrogenase) were resolved with the Tris-citrate system of Ayala et al. (1972).

Genestats (Black and Krafsur, 1985b) and BIOSYS (Swofford and Selander, 1982) were used to analyse the data. Weir and Cockerham's (1984) chi-square test for random mating was employed. Wright's (1978) analysis of allele frequencies in subdivided population was used to partition variance among all samples into the variance among cities and among locations within cities. Within city variance was estimated among sites within Houston ( 5 sites) and New Orleans (4 sites).

\section{RESULTS}

Allele frequencies in Ae. albopictus populations from nine locations in the United States are listed in table 1. Frequencies among mosquitoes in New Orleans and Houston are weighted means among collection sites. Tables 2 and 3 list allele frequencies at locations in New Orleans and Houston respectively. Heterozygosities at the 7 loci were approximately equal among mosquitoes in Houston and surrounding counties, New Orleans and Indianapolis. Heterozygosity was reduced in Jacksonville, Memphis and Evansville.

Nei's unbiased genetic distances (1978) were calculated among populations in the various cities (table 4). In New Orleans, Houston and Indianapolis the same alleles were found to be most common at each locus. The genetic distance between Houston and New Orleans was small as was the distance between Indianapolis and Houston. Memphis and Evansville were genetically similar but strongly differentiated from all other populations. The frequency of alleles at the HAD locus in Memphis and Evansville were in inverse proportions to those found in all other cities. The same was true of alleles at the IDH locus in Jacksonville. Allele E occured with high frequency at the ACON locus in the Jacksonville population but was only found in low frequency 


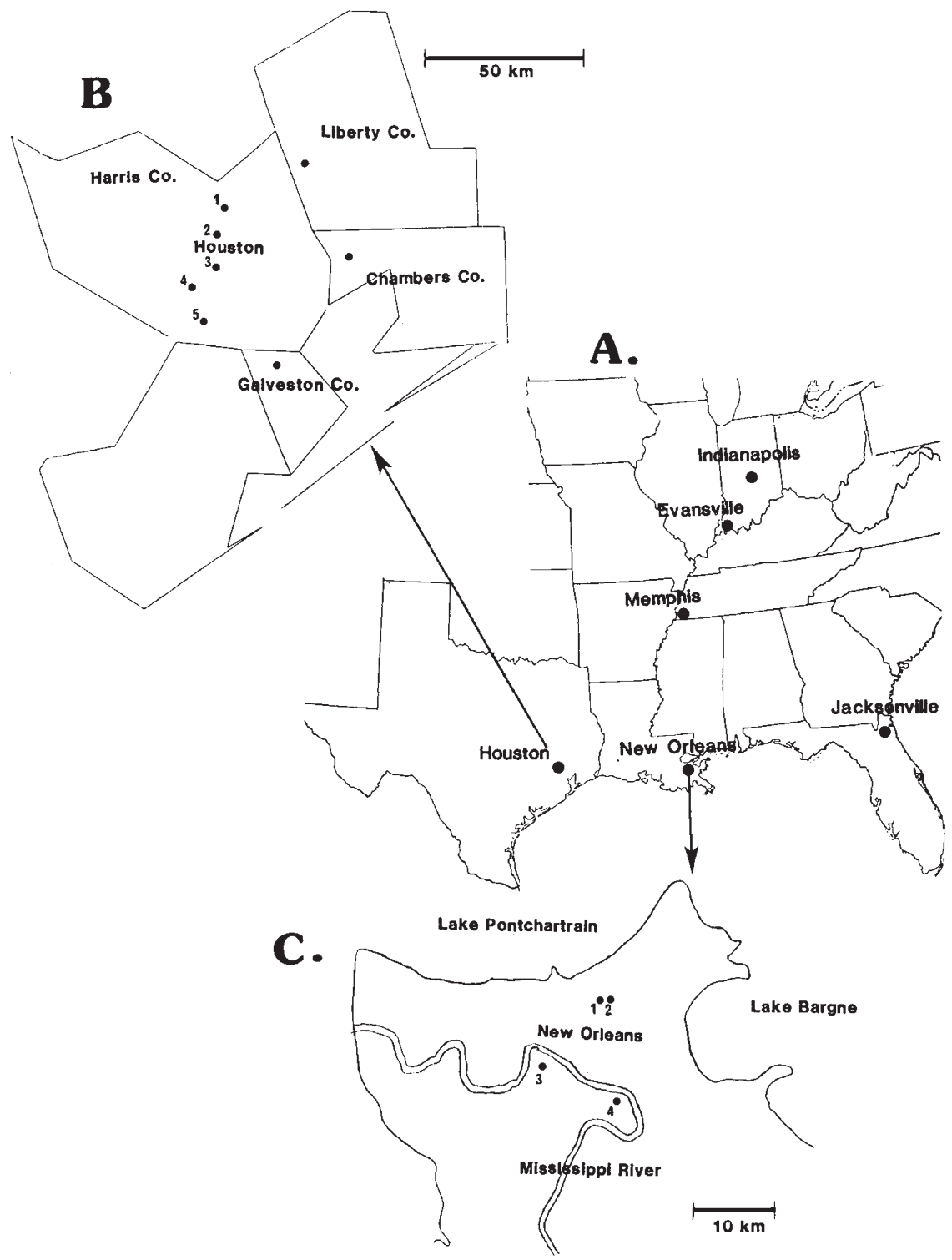

Figure 1 A. Cities in which Ae. albopictus was collected for this study. B. Collection locations in Houston, Texas and surrounding counties. $1=$ North, $2=$ North Central, $3=$ Central $1,4=$ Central $2,5=$ South. C. Collection sites in New Orleans, Louisiana. $1=$ North site $1,2=$ North site $2,3=$ Central, $4=$ Algiers.

in two other populations in Texas. The Jacksonville population was not genetically similar to any other in the study.

Eight alleles were detected which were unique to specific locations in Texas, New Orleans and Indianapolis. Two alleles were found only in New Orleans, five alleles were found only in Houston and surrounding counties and a single unique allele was found in Indianapolis. Two alleles were unique to Chambers County and one to Galveston
County. IDH allele D was found in high frequency at site \#2 in Houston close to other sampling sites. There were no alleles unique to either the Memphis, Evansville or Jacksonville populations.

Pairwise contingency chi-square tests indicated that allele frequencies were significantly different among all cities (analyses not shown). Table 5 lists the results of contingency chi-square analysis to test for homogeneity of allele frequencies among locations within cities. Populations within both 
Table 1 Allele frequencies and sample sizes $(N)$ at nine locations in the United States

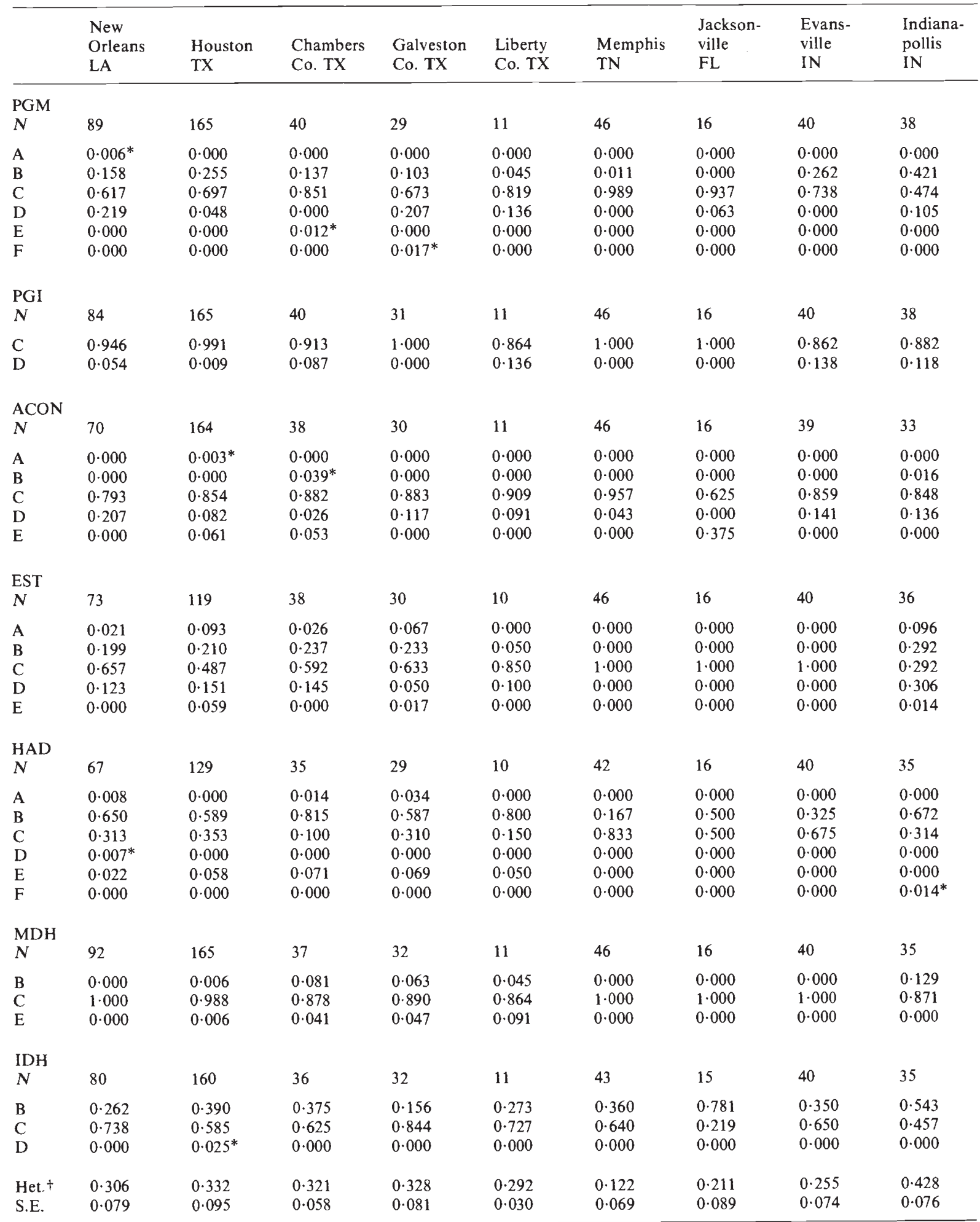

* This is the only location at which this allele was found.

$\uparrow$ Average expected genic heterozygosity and standard error among these 7 loci. 
Table 2 Allele frequencies and sample sizes $(N)$ at four locations in New Orleans

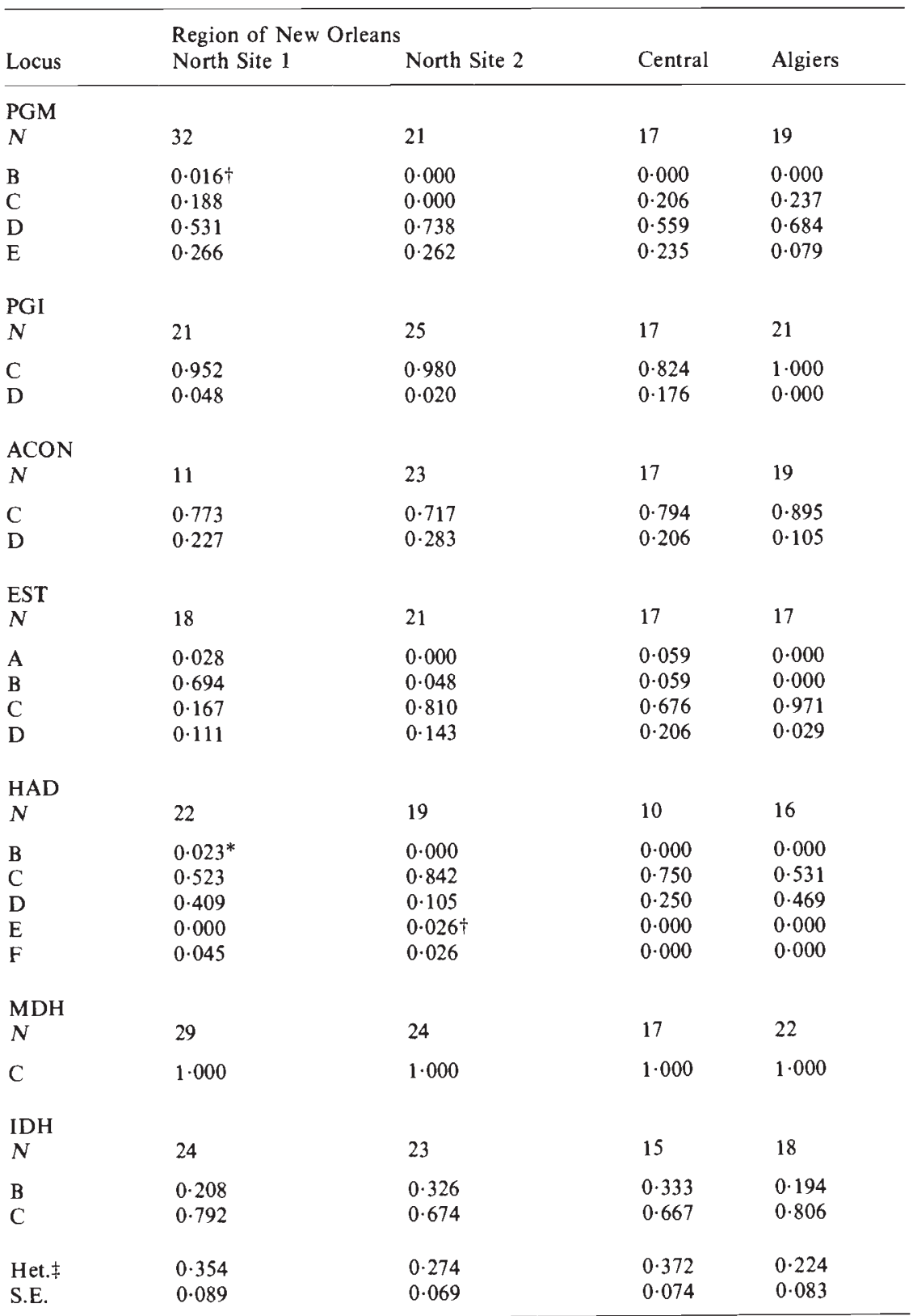

* This is the only location in New Orleans at which this allele was found

† This is the only location at which this allele was found.

$\$$ Average expected genic heterozygosity and standard error among these 7 loci.

New Orleans and Houston were significantly differentiated. The variance in allele frequencies among all locations was partitioned into the variance among cities and locations within cities. Table 6 shows that 77 per cent of the total variance among all sampling locations was attributable to differ- ences among locations within cities. The variance of allele frequencies at nearby locations was 4 times as great as the variation among cities.

Observed genotypic frequencies in adults collected in the field and F1 adults from field-collected eggs were compared with those expected under 
Table 3 Allele frequencies and sample sizes $(N)$ at five locations in Houston

\begin{tabular}{|c|c|c|c|c|c|}
\hline \multirow[b]{2}{*}{ Locus } & \multicolumn{2}{|c|}{ Region of Houston } & \multirow[b]{2}{*}{ Central 1} & \multirow[b]{2}{*}{ Central 2} & \multirow[b]{2}{*}{ South } \\
\hline & North & North Central & & & \\
\hline \multicolumn{6}{|l|}{ PGM } \\
\hline$N$ & 28 & 39 & 46 & 40 & 12 \\
\hline $\mathrm{C}$ & 0.357 & 0.231 & $0 \cdot 185$ & $0 \cdot 287$ & $0 \cdot 250$ \\
\hline $\mathrm{D}$ & 0.625 & 0.654 & 0.772 & 0.688 & 0.750 \\
\hline $\mathrm{E}$ & 0.018 & $0 \cdot 115$ & 0.043 & 0.025 & 0.000 \\
\hline \multicolumn{6}{|l|}{ PGI } \\
\hline$N$ & 28 & 40 & 47 & 40 & 10 \\
\hline $\mathrm{C}$ & $1 \cdot 000$ & 0.987 & $1 \cdot 000$ & 0.975 & $1 \cdot 000$ \\
\hline $\mathrm{D}$ & 0.000 & 0.012 & 0.000 & 0.025 & 0.000 \\
\hline \multicolumn{6}{|l|}{ ACON } \\
\hline$N$ & 27 & 40 & 47 & 40 & 10 \\
\hline A & 0.000 & 0.000 & 0.000 & 0.000 & $0.050^{\dagger}$ \\
\hline $\mathrm{C}$ & 0.722 & 0.875 & 0.926 & 0.850 & 0.800 \\
\hline $\mathrm{D}$ & $0 \cdot 204$ & 0.037 & 0.011 & 0.125 & $0 \cdot 100$ \\
\hline $\mathrm{E}$ & 0.074 & 0.087 & 0.064 & 0.025 & 0.050 \\
\hline \multicolumn{6}{|l|}{ EST } \\
\hline$N$ & 24 & 20 & 39 & 28 & 8 \\
\hline A & 0.063 & $0 \cdot 100$ & 0.090 & $0 \cdot 161$ & 0.000 \\
\hline B & $0 \cdot 250$ & $0 \cdot 325$ & 0.103 & 0.232 & 0.125 \\
\hline $\mathrm{C}$ & 0.438 & 0.375 & 0.603 & 0.429 & 0.688 \\
\hline $\mathrm{D}$ & $0 \cdot 250$ & $0 \cdot 125$ & 0.064 & $0 \cdot 179$ & $0 \cdot 188$ \\
\hline $\mathrm{E}$ & 0.000 & 0.075 & $0 \cdot 141$ & 0.000 & 0.000 \\
\hline \multicolumn{6}{|l|}{ HAD } \\
\hline$N$ & 15 & 40 & 25 & 40 & 9 \\
\hline $\mathrm{C}$ & 0.800 & 0.712 & 0.520 & 0.387 & 0.778 \\
\hline $\mathrm{D}$ & $0 \cdot 200$ & $0 \cdot 287$ & 0.460 & 0.450 & $0 \cdot 167$ \\
\hline$F$ & 0.000 & 0.000 & 0.020 & $0 \cdot 162$ & 0.056 \\
\hline \multicolumn{6}{|l|}{$\mathrm{MDH}$} \\
\hline$N$ & 28 & 40 & 47 & 40 & 10 \\
\hline B & 0.000 & 0.012 & 0.011 & 0.000 & 0.000 \\
\hline C & $1 \cdot 000$ & 0.987 & 0.989 & 0.975 & 1.000 \\
\hline $\mathrm{E}$ & 0.000 & 0.000 & 0.000 & $0.025^{*}$ & 0.000 \\
\hline \multicolumn{6}{|l|}{ IDH } \\
\hline$N$ & 26 & 40 & 45 & 40 & 9 \\
\hline B & 0.596 & 0.487 & 0.144 & 0.462 & 0.278 \\
\hline $\mathrm{C}$ & 0.404 & 0.412 & 0.856 & 0.537 & 0.722 \\
\hline D & 0.000 & $0 \cdot 100 \dagger$ & 0.000 & 0.000 & 0.000 \\
\hline Het. $\ddagger$ & 0.349 & $0 \cdot 364$ & 0.277 & $0 \cdot 380$ & 0.296 \\
\hline S.E. & 0.099 & $0 \cdot 106$ & 0.092 & $0 \cdot 101$ & 0.078 \\
\hline
\end{tabular}

* This is the only location in Houston at which this allele was found.

$\dagger$ This is the only location at which this allele was found.

$\ddagger$ Average expected genic heterozygosity and standard error among these 7 loci.

random mating. We found 9 of 81 tests to show significant deviations from expectations. This was only slightly more than expected with a type I error rate of 5 per cent $(0.05 \times 81=4$ significant observa- tions). Values were homogeneously distributed among samples and loci. All significant values were attributable to an excess of homozygotes suggesting a slight inbreeding effect. 
Table 4 Nei's unbiased genetic distances among United States populations

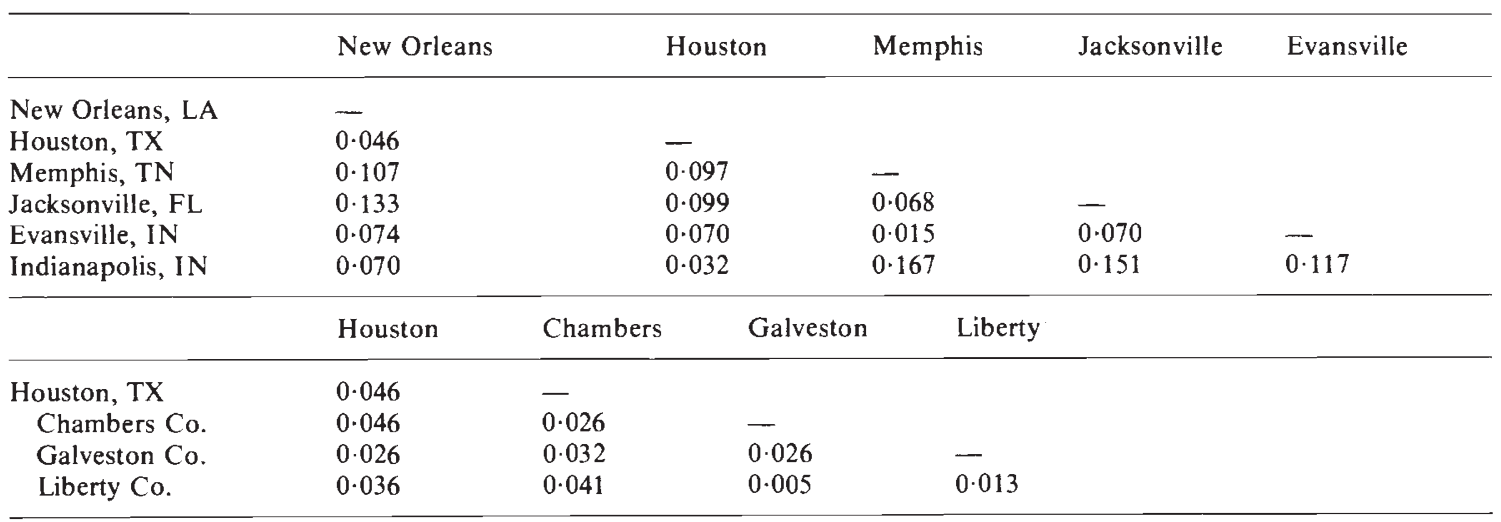

Table 5 Chi-square contingency test for homogeneity of allele frequencies among populations in New Orleans and Houston

\begin{tabular}{|c|c|c|c|c|}
\hline Locus & \multicolumn{2}{|c|}{ New Orleans } & \multicolumn{2}{|c|}{ Houston } \\
\hline PGM & 9 & $17 \cdot 45^{*}$ & 8 & $16 \cdot 47^{*}$ \\
\hline PGI & 3 & $13 \cdot 65^{* *}$ & 4 & $3 \cdot 91$ \\
\hline ACON & 3 & $4 \cdot 05$ & 12 & $39 \cdot 33^{* * *}$ \\
\hline EST & 9 & $87 \cdot 79 * * *$ & 16 & $37 \cdot 25^{* *}$ \\
\hline HAD & 12 & $20 \cdot 33$ & 8 & $42 \cdot 47^{* * *}$ \\
\hline MDH & - & - & 8 & $8 \cdot 09$ \\
\hline IDH & 3 & $3 \cdot 32$ & 8 & $66 \cdot 31^{* * *}$ \\
\hline Total & 39 & $146 \cdot 60 * * *$ & 64 & $213 \cdot 83^{* * *}$ \\
\hline
\end{tabular}

* $P \leqq 0.05, * * P \leqq 0.01, * * * P \leqq 0.001$.

\section{DISCUSSION}

The relatively high levels of genetic variation and the existence of unique alleles in Houston, New Orleans and Indianapolis suggest large and possibly independent introductions in these cities. The high heterozygosity in the Indianapolis population, approximately $1000 \mathrm{~km}$ north of Houston and New Orleans, indicates that there may have been a large inland introduction. The small genetic distance between Evansville and Memphis (approx $400 \mathrm{~km}$ apart) suggests inland transport or migration of populations.
Low heterozygosities, an absence of unique alleles and high frequencies of alleles less common in the general population were found in Memphis, Evansville, and Jacksonville. These results are consistent with the hypothesis that a substantial population bottleneck occurred during or after the founding of populations in these cities. The bottleneck may have resulted from a small number of founding individuals or may have been generated through repeated attempts at control. Because of the intensive control efforts mounted in all cities it is impossible to determine when such bottlenecks might have occured. For example, Ae. albopictus had been found and eliminated at three locations in western Memphis before we sampled the population.

We found significant differentiation of allele frequencies within and among cities. Most of the variance in allele frequencies was attributable to local differentiation. The most parsimonious explanation of this result is that much genetic drift accompanied the establishment of local populations in New Orleans and Houston and local gene flow was sufficiently restricted to maintain differentiation. Alternatively, populations in cities may have been panmictic but local selection pressures led to microdifferentiation. Because there was less variance among cities than among sites within cities this explanation further requires that a similar range of microhabitats exist in both cities.

Table 6 The variance in allele frequencies among all locations partitioned into the variance among cities and among locations within cities. Variance components are combined among loci

\begin{tabular}{lll}
\hline Source & Variance & $\%$ Total Variance \\
\hline Locations within cities & 0.212 & $76 \cdot 6 \%$ \\
Among cities & 0.065 & $23.4 \%$ \\
Among all locations & 0.277 & \\
\hline
\end{tabular}


While this is possible it seems far less likely than the model of genetic drift.

The existence of genetic drift indicates that local populations were founded by few parents. Tyres present a sparse oviposition resource. A few gravid females may have located and oviposited in a group of discarded tyres. The offspring, failing to locate other oviposition sites or other mates, might have mated with siblings and oviposited in the same tyres. Inbreeding developed as sibling matings continued.

This model would account for the inbreeding observed in some populations as well as the large numbers of alleles unique to single locations within cities. Alleles which were in low frequency in the overall population would increase in local subpopulations. Other studies of local breeding structure in mosquitoes suggest that this model may apply generally to container breeding mosquitoes. Local breeding structure studies on a tree hole mosquito, Ae. triseriatus (Say) (Matthews and Craig, 1980; Matthews, 1983) indicated local panmixia but homozygote excesses indicative of inbreeding. A similar study of the sympatric tree hole mosquito, Ae. hendersoni (Cockerell) (Matthews and Munstermann, 1983) demonstrated significant local differentiation of subpopulations.

This initial survey of a species in the early stages of colonisation suggests that drift may initially play an important role in differentiating populations. However, no local breeding structure studies have been made of Ae. albopictus populations in its native habitat. It is therefore unknown whether the breeding structure of Ae. albopictus in the United States is a consequence of recent colonisation or a characteristic of container breeding species. Future surveys will indicate whether populations both within and among cities remain differentiated. It seems possible, given the rapid spread already exhibited by Ae. albopictus, that populations may become panmictic within a short time.

Acknowledgements We thank Bill Kelly and Sam Jones of the Memphis County Public Health Dept., Ed Bowles of the Mississippi Bureau of Environmental Health, George Carmichael, Mike Carrol, and Mike Andis of New Orleans Mosquito Control, and Bob Barnett, Mark Marmon and Taweesak Wuithiranyagool of the Harris County Mosquito Control District, Houston for their help and hospitality during field collections. Eggs from Jacksonville, Florida were shipped to Notre Dame by P. G. Gregory and B. Peacock of the Jacksonville Mosquito Control Agency. Eggs and adults from Evansville and Indianapolis, Indiana were collected and shipped to Notre Dame by M. Sinsko, Medical Entomologist for Indiana. This work was supported by NIH training grant 5 T32 AI-07030 and NIH grant 5R01 AI-21443 to K.S.R.

\section{REFERENCES}

AYAla, F. J., POWEll, J. R., TRACEY, M. L., MOURAO, C. A., AND PEREZ-SALAS, S. 1972. Enzyme variability in the Drosophila willistoni group. IV. Genic variation in natural populations of Drosophila willistoni. Genetics, 70, 113-139.

BAKER, R. C. AND STEBbINS, G. L. 1965. The Genetics of Colonizing Species. Academic Press, New York.

BELKIN, J. N. 1962. Mosquitoes of the South Pacific (Diptera, Culicidae), 2 vols. University of California Press, Berkeley.

BLACK, W. C. AND KRAFSUR, E. S. 1984. Vertical slab gel electrophoresis on a large number of samples: an apparatus with the capacity for central cooling. Anal. Biochem., 138, 210-216.

BLACK, W. C., IV AND KRAFSUR, E. S. 1985a. Electrophoretic analysis of genetic variability in the house fly (Musca domestica L). Biochem. Genet., 23, 191-201.

BLACK, W. C., IV AND KRAFSUR, E. S. 1985b. A FORTRAN program for analysis of genotypic frequencies and description of the breeding structure of populations. Theor. Appl. Genet., 70, 484-490.

BRYANT, E. H., VAN DIJK, H. AND VAN DELDEN, W. 1981. Genetic variability of the face fly, Musca autumnalis De Geer, in relation to a population bottleneck. Evolution, 35, 872-881.

DObzhansky, TH. 1970. Genetics of the Evolutionary Process. Columbia University Press, New York.

EADS, R. B. 1972. Recovery of Aedes albopictus from tires shipped to United States ports. Mosq. News, 32, 113-114.

ELLIOTT, S. A. 1980. Aedes albopictus in the Solomon and Santa Cruz Islands, South Pacific. Trnas. R. Soc. Trop. Med. Hyg., 74, 747-748.

FENNER, F. 1965. Myxoma virus and Oryctolagus cuniculus: two colonizing species. In Baker, H. G. and Stebbins G. L. (eds.) The Genetics of Colonizing Species, Academic Press, New York, pp. 485-499.

HARDY, D. E. 1960. Culicidae. In Zimmerman, E. C. (ed.) Insects of Hawaii, vol. 10, University of Hawaii Press, pp. 18-22, 81-90.

HAWLEY, W. A., REITER, P., COPELAND, R. S., PUMPUNI, C. B. AND CRAIG, G. B. 1987. Aedes albopictus in North America: Probable introduction in tires from Northern Asia. Science, 236, 1114-1116.

HO, E. C., CHAN, K. L. AND CHAN, Y. C. 1973. The biology and bionomics of Aedes albopictus (Skuse). In Chan, Y. C., Chan, K. L. and Ho, B. C. (eds.) Vector Control in Southeast Asia, pp. 125-143.

HUANG, Y. M. 1972. Contributions to the mosquito fauna of southeast Asia. XIV. The subgenus Stegomyia of Aedes in southeast Asia. I. The scutellaris groups of species. Contrib. Am. Ent. Inst. (Ann Arbor)., 9, 1-109.

JOYCE, C. R. 1961. Potentialities for accidental establishment of exotic mosquitoes in Hawaii. Proc. Hawaiian, Entomol. Soc., 17, 403-413.

KNIGHT, K. L. AND STONE, A. 1977. A catalog of the Mosquitoes of the World (Diptera: Culicidae), 2nd edition. Thomas Say Foundation, vol. 6. Entomol. Soc. Am., 610 pp.

LEWONTIN, R. C. 1974. The Genetic Basis of Evolutionary Change. Columbia University Press, New York.

MATTHEWS, T. C. AND CRAIG, G. B., JR. 1980. Genetic heterozygosity in natural populations of the tree hole mosquito Aedes triseriatus. Ann. Entomol. Soc. Am., 73, 739-743.

MATthewS, T. C. 1983. Population genetics of the tree hole mosquito Aedes triseriatus: no correlation between Est-6 and larval habitat. Heredity, 52, 133-139. 
MATTHEWS, T. C. AND MUNSTERMANN, L. E. 1983. Genetic diversity and differentiation in northern populations of the tree hole mosquito Aedes hendersoni (Diptera: Culicidae). Ann. Entomol. Soc. Am., 76, 1005-1010.

MAYR, E. 1963. Animal Species and Evolution. Belknap Press of Harvard University Press, Cambridge, Mass.

NEl, M. 1978. Estimation of average heterozygosity and genetic distance from a small number of individuals. Genetics, 89 , 583-590.

PARSONS, P. A. 1983. The Evolutionary Biology of Colonizing Species. Cambridge University Press, Cambridge.

PASHLEY, D. N. AND PASHLEY, D. P. 1983. Observations on Aedes (Stegomyia) mosquitoes in Micronesia and Melanesia. Mosq. Syst., 15, 41-49.

REITER, P. AND DARSIE, R. F. JR. 1984. Aedes albopictus in Memphis, Tennessee (U.S.A): An achievement of modern transportation? Mosq. News, 44, 396-399.

SMITH, C. E. G. 1956. The history of dengue in tropical asia and its relationship to the mosquito Aedes aegypti. J. Trop. Med. Hyg., 59, 243-252.
SPRENGER, D. AND WUITHIRANYAGOOL, T. 1986. The discovery and distribution of Aedes albopictus in Harris County, Texas. J. Am. Mosq. Cont. Assoc., 2, 217-219.

SWOFFORD, D. L. AND SELANDER, R. B. 1981. BIOSYS-1: a FORTRAN program for the comprehensive analysis of electrophoretic data in population genetics and systematics. J. Hered., 72, 281-283.

TAYLOR, C. E. AND GORMAN, G. C. 1975. Population genetics of a "colonizing" lizard: Natural selection for allozyme morphs in Anolis grahami. Heredity, 35, 241-247.

WEIR, B. S. AND COCKERHAM, C. C. 1984. Estimating $F$-statistics for the analysis of population structure. Evolution, 38 , 1358-1370.

WRIGHT, S. 1978. Evolution and the Genetics of Populations. Vol. IV. Variability Within and Among Natural Populations. University of Chicago Press, Chicago.

YONG, H. S., CHAN, K. L. AND DHALIWAL, S. S. 1981. Genetics of glucose phosphate isomerase and phosphoglucomutase in Aedes albopictus (Diptera: Culicidae). Theor. Appl. Genet., 59, 345-348. 